\title{
LELIA GALVÃo
}

é formada em Letras

Neo-latinas
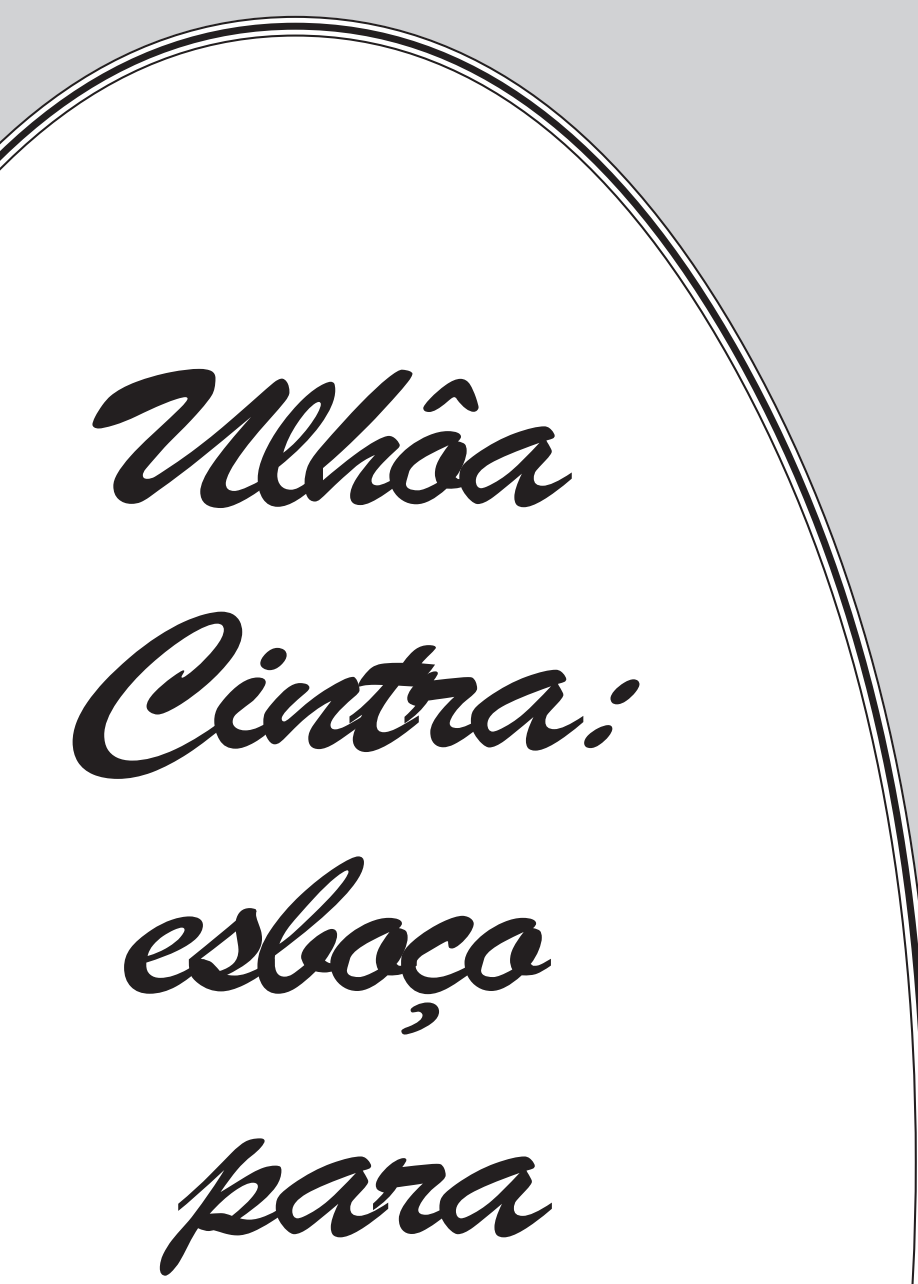

cen

retrata 
oi um homem talentoso e creio que sabia disso. Sua mente era lúcida demaıs para que não reconhecesse a própria inteligência, ou que a negasse aos outros. Assim foi que no decurso de uma vida longa e produtiva salientou-se em áreas diversas, como médico, educador, pesquisador, mas acima de tudo cientista, sempre em busca de conhecimento dentro da esfera que lhe interessava na ocasião. Penso que nunca deixou de ser cientista, fizesse o que fizesse. A ciência foi sua paixão maior, a forca motriz de toda a sua atividade.

Todavia, nãoé do Ulhôa Cintra profissional brilhante que quero falar agora, mas do homem Ulhôa Cintra a quem conheci muito bem. Traços desse homem acorrem à minha mente neste momento, como que num caleidoscópio movendo-se em giro muito rápido, espelhando imagens, um flagrante, uma exclamação, seu riso de nariz franzido, uma frase, um gesto, gostos, atitudes, hábitos, pequenas manias, curiosidades, vezos, ingenuidades, suas bravezas, o amor enorme pelas filhas, o orgulho dos netos, os encantamentos meio acanhados com os bisnetos, a imensa riqueza de noventa e um anos de vida desdobrando-se num painel de nuances impossível de ser abarcado.

Vejo-o como um humanista, irredutível na defesa dos direitos humanos, mas também como um homem humanitário, capaz de sensibilizar-se com o sofrimento alheio e, sem disso fazer alarde, socorrer pessoas simples que lhe pediram ajuda.

Muitos daqueles que não o conheceram bem julgaram-no frio, arrogante, hermético, distante. Não nego que à primeira vista causasse essa impressão. Era um homem austero, cioso de sua afetividade, manifestando-a de forma meio velada, como que temerosa da própria expansão. Na intimi- dade, contudo, essa imagem suavizava-se e ele era o pater familias, sempre presente, esteio e força dos seus. Autoritário, sim, uma característica pessoal, nunca abrandada. Contudo, jamais foi um tirano, intolerante a contestações. Gostava muito das reuniões familiares, de conversar com as filhas, de ouvi-las, e aos netos, procurando transmitir-lhes sua experiência, suas vivências tão ricas, seus princípios, o culto à liberdade de pensamento, o respeito aos demais, a dignidade para consigo, a fidelidade aos próprios valores.

Enquanto evoco Ulhôa Cintra, julgo que dois grandes traços impõem-se à apreensão de sua figura. O mais marcante deles era uma imensa sabedoria de vida, que o tornava quase um adivinho, como que possuidor de alguma fórmula mágica que o levava a antever fatos ainda não perceptíveis para o comum das pessoas. O outro era uma integridade pessoal absoluta, tanto para consigo quanto em seus relacionamentos com os demais. Nunca o ouvi dizer alguma inverdade, como nunca o vi agir de forma interesseira com quem quer que fosse. Dizia exatamente o que pensava, sem se ater a julgamentos alheios discordantes dos seus. Certamente isso lhe trouxe conflitos e dissabores, mas Ulhôa Cintra jamais deixou de ser fiel a si mesmo.

Como conhecia a extensão de seu talento, também conhecia as próprias limitações. Assim é que nunca foi um financista, por exemplo, solicitando que outros mais capacitados o orientassem numa esfera que lhe era estranha e que nunca o atraiu. Da vida doméstica pouco sabia, manifestando um espanto muito verdadeiro quando se inteirava de algum pormenor que the havia escapado. Ficou famosa na família a crônica de um célebre jantar em que ele foi convidando pessoas sem dar ciência do núme- 
ro destas à esposa, a quem deixou em palpos de aranha... Também dirigia carro de forma sofrível, não sendo raras as batidas, em que ele havia "relado" no outro. Adorava caminhar a pé e muitas vezes saí com ele, ouvindo histórias de sua infância, andando de bicicleta por cima de um muro, para inveja de seus mais de cinquienta primosirmãos, de sua vida escolar no Ginásio do Estado e depois na Faculdade de Medicina, as lutas dos primeiros anos de vida, o impulso dado à carreira pelo ano que passou em Boston, em 1942, visto como uma espécie de incursão para dentro do futuro, o retorno, as lembranças dos amigos e companheiros de trabalho, suas admirações, suas decepções, desafios, vitórias, derrotas. Outras vezes seu ânimo tendia a tornarse especulativo e seu pensamento prendiase às transformações que vinham ocorrendo no mundo, a importância do papel das universidades nesse novo contexto que as facilidades de comunicação haviam modificado, que a tecnologia havia impelido para sendas de alcance ainda insuspeitado, enfatizando sempre o primado que o pensamento puro deveria manter sobre o fascínio das máquinas, o exercício da meditação, a troca de idéias, a liberdade da criatividade, o uso da imaginação... Não eram sempre filosóficas ou evocativas as nossas conversas. Inúmeras vezes falava eu, e ele nunca se negou a me acompanhar, demonstrando interesse e até mesmo curiosidade em campos que não eram nada familiares. Aliás, curiosidade foi um traço que ele nunca perdeu, aliado à capacidade de surpreender-se, manifestando essa surpresa muitas vezes de forma efusiva, como um menino diante de um brinquedo novo.

Vejo-o ainda no jardim de sua casa, nas tardes bonitas dos fins de semana estudando, com uma pilha de livros ou de revistas médicas ao lado. Vejo-o feliz ao lado da esposa festejando suas bodas de ouro. Vejoo em suas viagens para a Suíça no inverno, esquiando na neve, apesar da idade. Vejoo abrindo um vinho, comendo balas de ovos, jogando bilboquet, ouvindo o noticiário, colocando mal as vírgulas em seus trabalhos, observando as fases da lua ou alguma casa que lhe chamasse a atenção em suas voltas pelo bairro, chegando do consultório, com sono cedo, pedindo limonada, tomando café sem açúcar, mexendo em seus papéis, em atividade constante, enquanto pôde mantê-la.

O que resta ainda dizer? Como captar em algumas linhas a figura de alguém, de qualquer pessoa? Como reproduzir a imagem de um universo espiritual tão amplo, tão cheio de vida, como capturar a singularidade de um ser humano?

Assim sendo, creio que só resta dizer que escrever sobre ele trouxe-me o consolo de revivê-lo para outrem na medida do possível, ao mesmo tempo em que renovava dentro de mim a dor de havê-lo perdido, pois se admirei o professor doutor Antonio Barros de Ulhôa Cintra, amei profundamente o homem Antonio Barros de Ulhôa Cintra, meu pai. 